\title{
Analysis and automatic segmentation of images for lungs regions extraction in X-ray chest
}

\section{Analisis y segmentación automática de imágenes para extraer las regiones pulmonares en radiografías de torax}

QUINTANILLA-DOMÍNGUEZ, Joel †*, YAÑEZ-VARGAS, Juan Israel, BUTANDA-SERRANO, Miriam and SÁNCHEZ-TORRECITAS, Enrique

Universidad Politécnica de Juventino Rosas, Dept. Engineering in Networks and Telecommunications \& Master in Engineering-Intelligent Systems, Mexico.

ID $1^{\text {st }}$ Author: Joel, Quintanilla-Domínguez / ORC ID: 0000-0003-2442-2032

ID $1^{\text {st }}$ Coauthor: Juan, Yañez-Vargas / ORC ID: 0000-0001-5749-8442

ID $2^{\text {nd }}$ Coauthor: Miriam, Butanda-Serrano / ORC ID: 0000-0003-1405-0204

ID $3^{\text {rd }}$ Coauthor: Enrique, Sánchez-Torrecitas / ORC ID: 0000-0002-5395-6749

DOI: $10.35429 / J Q S A .2020 .21 .7 .18 .27$

Received September 05, 2020; Accepted December 01, 2020

\begin{abstract}
One of the main disease caused by the COVID-19 in the humans is the pneumonia. This disease mainly attacks the lungs and one of the effective methods for diagnosis is through X-ray chest analysis. Due this in this work a methodology that allow the segmentation and analysis of regions that belong to the lungs in images of X-ray chest is presented. This methodology is based mainly in the implementation of some digital image processing techniques such as: contrast enhancement, segmentation, binarization and the application of morphological operations as the erosion and dilatation.
\end{abstract}

Viral pneumonia, bacterial pneumonia, image processing, analysis and segmentation of image

\begin{abstract}
Resumen
Una de las principales afecciones ocasionadas por el COVID-19 en los seres humanos es la neumonía, enfermedad que ataca a los pulmones y uno de los métodos más eficaces para el diagnóstico certero de esta enfermedad es mediante el análisis de una radiografía torácica. Debido a esto en este trabajo se presenta una metodología que permite la segmentación y análisis de regiones que pertenecen a pulmones en imágenes de rayos $\mathrm{X}$ de torax. La metodología está basada principalmente en la implementación de algunas técnicas de procesamiento digital de imagen tales como: mejora del contraste, segmentación, binarización y la aplicación de operaciones de morfología matemática como la erosión y la dilación.
\end{abstract}

Neumonía viral, procesamiento de imagen, análisis y segementación de imagen

\footnotetext{
* Correspondence to Author (email: jquintanilla_ptc@upjr.edu.mx)

$\dagger$ Investigador contribuyendo como primer autor.
} 


\section{Introduction}

In recent months, millions of people around the world have contracted the coronavirus disease 2019 (COVID-19), which is caused by the SASR-COV-2. Currently, various investigations have shown that the most recurrent symptoms due to COVID-19 are fever, dry cough, fatigue and dyspnea. According to (Goërtz, et al., 2020) it shows that three months after COVID-19, more than $90 \%$ of the patients presented symptoms, with fatigue and dyspnea being the most reported. However, symptoms related to lung diseases were also reported as frequent, including Chronic Obstructive Pulmonary Disease (COPD) as well as Acute Hypoxemic Respiratory Failure (HARF) (Figueira Gonçalves, García-Talavera, Golpe, \& Gurbani, 2020). These last two diseases, if not treated properly, can cause complications such as: heart problems, lung cancer, high blood pressure in pulmonary arteries and pneumonia, the latter being the subject of interest for the development of this work.

According to the World Health Organization, pneumonia is a type of acute respiratory infection that affects the lungs and is generally transmitted by direct contact with infected people (WHO, 2020). Pneumonia is classified mainly into typical or bacterial pneumonia and atypical pneumonia produced by viruses or atypical Bacterium (Echevarría, Miguel, Artigao, \& del Castillo Martín, 2014). For the diagnosis of this disease, the doctor relies mainly on a physical examination specifically in the pulmonary region in order to detect any abnormal sound that suggests the presence of nemonia. If there is a suspicion of the disease, the doctor will request one of the following tests: blood chemistry, chest X-ray, pulse oximetry, sputum test and if the patient is over 65 years old, a chest CT image and culture of the chest may be included. pleural fluid (Mayo Clinic, 2020).

In (Polap \& Wozniak, 2017) they present a lung segmentation technique based on graphic processing methods and a swarm algorithm. The swarm algorithm was used to extract particular regions of information and then use them in a detector based on a convolutional neural network.
In (Naranjo Alcázar, Bosch Roig, Sanz Requena, \& Vázquez Martínez, 2016) present an automatic method of image analysis and segmentation for the detection of pulmonary nodules in chest radiographs. The segmentation of the lungs is mainly based on the application of the k-means clustering algorithm in addition to the application of mathematical morphology operations.

In (Joykutty, Satheeshkumar, \& Samuvel, 2016) present a method for the automatic detection of tuberculosis using adaptive thresholding in chest radiography. The method consists of three stages. The first stage consists of segmentation of the region of the lungs using adaptive thresholding. The second stage consists of a feature extraction, finally in the third stage, a k-nn classifier is implemented to decide whether the image is normal or not. In this work, the second stage is of interest since this is where the region of the lungs is segmented, which is based on the implementation of image processing techniques such as contrast enhancement, binarization and the application of the morphology operation. math. It is important to highlight that part of this methodology was the one used in the present work for the segmentation of lung regions in chest radiographs.

This work focuses on the analysis of chest X-ray images in order to segment the lung region and thus help the doctor to improve the diagnosis of viral or bacterial pneumonia. For this, a methodology based mainly on image processing techniques such as contrast enhancement, segmentation, binarization and the application of mathematical morphology operations is implemented.

The work presented here is organized as follows: this section shows the introduction to the problem, as well as a brief state of the art on which the work is focused. Section 2 describes the development and implementation of the methodology. The results are shown in section 3 . Finally, section 4 presents the conclusions of the work carried out. 


\section{Proposed methodology}

\section{Database}

The main requirement for image analysis is the database. In this work, the proposed methodology was applied to the database of chest radiography images known as Chest $\mathrm{x}$-Ray Images Pneumonia. This database is classified into pneumonia and normal images. In turn, pneumonia images are classified as viral pneumonia and bacterial pneumonia images (Mooney, 2018). Figure 1 shows three chest xray images with a normal diagnosis, pneumonia due to Bacterium and pneumomy due to viruses, respectively.

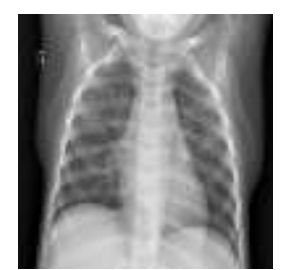

(a)

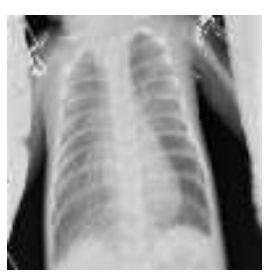

(b)

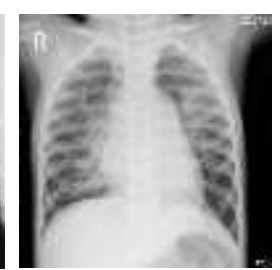

(c)
Figure 1 Chest X-ray images extracted from the database. (a) Radiograph with normal diagnosis. (b) X-ray with diagnosis of bacterial pneumonia. (c) X-ray with virus diagnosis

\section{Contrast enhancement}

Image enhancement techniques are generally used to highlight one or some characteristics that are of interest in order to make their perception simpler for the human visual system (Quintanilla, Ojeda, Ruelas, \& Yañez, 2019). Improvement techniques can be grouped into two categories, techniques in the spatial domain and techniques in the spatial domain. In this work, a technique is applied in the spatial domain since these are characterized by the direct manipulation of the image pixels (Gonzalez \& Woods, 2002).

In the proposed methodology, the technique to be implemented as a contrast enhancement is the negative of the image. This is a pixel operation in which the value of the pixels of the regions that are light in dark and those that are dark in light is altered.
This image improvement can be very useful when you want to appreciate bright details in the image, that is, when there are bright regions in a dark background, for example in the case of chest X-rays, it is better to differentiate the region corresponding to the lung in order to find the lesions caused by pneumonia. The operation to make the negative of an image is defined as:

$G=(L-1)-I$

Where $G$ is the negative of the original image $\mathrm{I}$ and $\mathrm{L}$ is the highest level of gray intensity in the original image. Figure 2 shows the original images and images processed by applying the image negative.
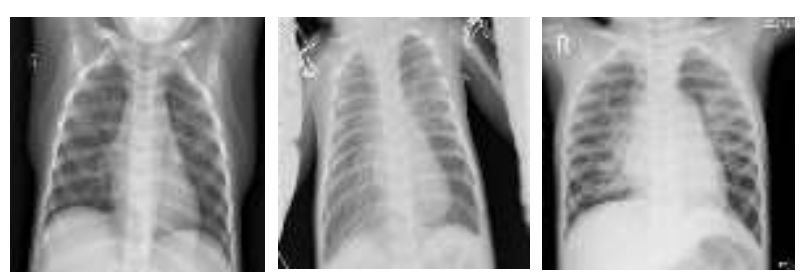

(a)
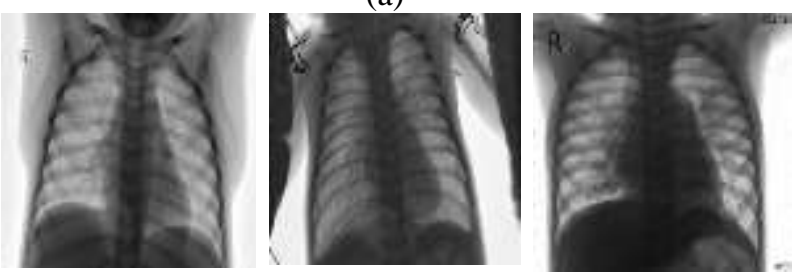

(b)

Figure 2 Contrast enhancement applying image negative. (a) Original chest radiograph images. (b) Chest X-ray images processed with the image negative

\section{Segmentation}

Segmentation is one of the most important stages of image processing and the purpose of this is to divide the image into small regions with respect to one or more characteristics such as: the level of gray intensity, color or texture. Gray level image segmentation techniques are generally based on one of the properties of gray level values such as discontinuity and similarity.

In this work, the objective of segmentation is to separate the X-ray image into different regions such as the fundus, lungs and bones, as well as tissue. To do this, a similaritybased technique known as multiple thresholding will be used using the Otsu method. Otsu's method of multiple thresholding or multithresholding allows to group the pixels of an image in several regions: 


$$
\begin{aligned}
& C_{0}=\left\{1, \ldots, u_{1}\right\}, \\
& C_{1}=\left\{u_{1}+1, \ldots, u_{2}\right\}, \ldots, \\
& C_{n}=\left\{u_{n}, \ldots, L-1\right\}
\end{aligned}
$$

Where $\mathrm{L}$ is the maximum value of gray levels of a pixel and where each class groups all the pixels up to a threshold obtained by Otsu, being:

$U=\left\{u_{1}, u_{2}, \ldots, u_{n}\right\}$

the set of thresholds obtained. The way that Otsu's method selects the threshold value is by maximizing the variance between the regions, $\sigma^{2}$,

$$
U=\underbrace{\operatorname{argmax}}_{1 \leq u_{1}<u_{2} \ldots<u_{n}<L}\left\{\sigma^{2}\right\}
$$

And the variance between the groups can be determined as:

$$
\sigma^{2}=\sum_{k=1}^{n} \omega_{k}\left(\mu_{k}-\mu_{T}\right)^{2}
$$

$$
\begin{aligned}
& \text { Where: } \\
& \mu_{k} \sum_{i \in C_{k}} \frac{i * p_{i}}{\omega_{k}} \\
& \omega_{k}=\sum_{i \in C_{k}} p_{i}, \omega_{1}=\sum_{i=1} p_{i}, \ldots, \omega_{n}=\sum_{i=u_{n+1}}^{L-1} p_{i} \\
& \mu_{T}=\sum_{i \in C_{k}} \mu_{k}=\sum_{i=1}^{L-1} i * p_{i}
\end{aligned}
$$

Where $\mu \mathrm{k}$ is the mean of the group or region $\mathrm{Ck}, \mu \mathrm{k}$ is the probability that the pixels belong to class $\mathrm{Ck}, \mu \mathrm{T}$ is the global mean of the image, and pi is the pixels with intensity of gray level i. (Merzban \& Elbayoumi, 2019) (Gil, Torres, \& Ortiz, 2004). As can be seen in Figure 3 , the images are shown segmented by the multithreshold Otsu method. To carry out this task, two threshold values were determined to segment the image into three regions. These values were obtained optimally by applying a simple Otsu thresholding.
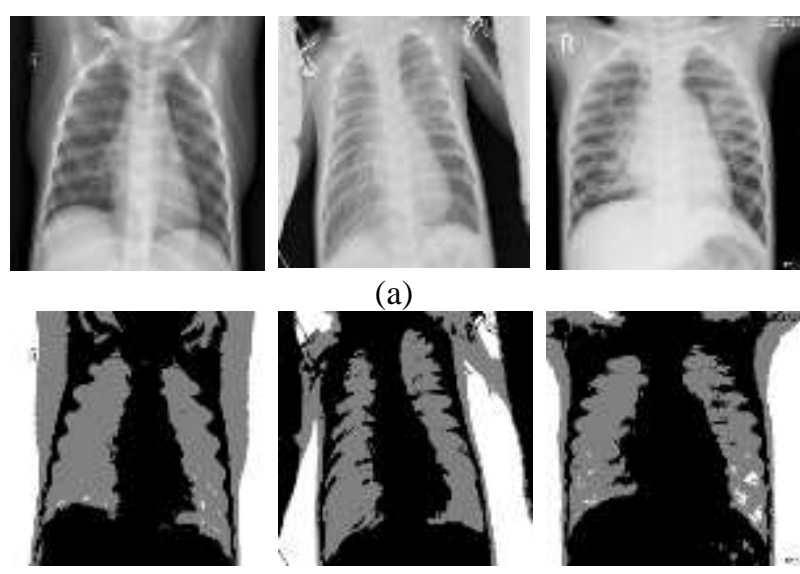

(b)

Figure 3 Image segmentation applying the multithreshold Otsu method. (a) Original chest radiograph images. (b) Chest X-ray images segmented by multithreshold Otsu

\section{Binarization}

Binarization is also an image segmentation, but in this case it divides it into only two regions by means of a threshold value (u), that is:

\section{Si $I(i, j) \geq u$ the pixel value is 1} $\{$ Si $I(i, j)<u$ the pixel value is 0

where $I(i, j)$ is defined as the intensity value of a pixel in the image. In this work, once the image is segmented into the fundus, lungs and bones, as well as the tissue, now the objective is to have an image where the region of the lungs and bones can be differentiated from the rest of the regions present in the image of the radiography. Figure 4 shows the binary images where the regions corresponding to lungs and bones are highlighted.
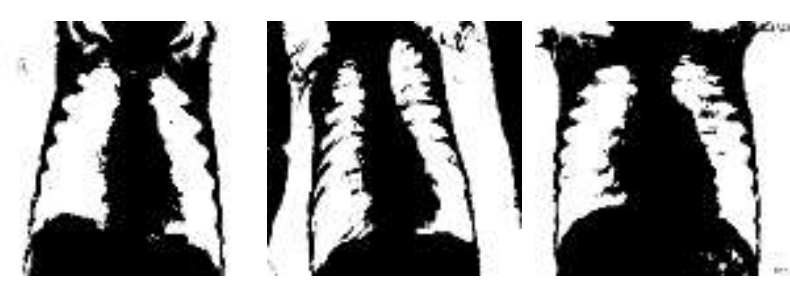

Figure 4 Segmented Image Binarization Process

The objective of this work is to segment the region of the lungs and in Figure 4 the region corresponding to the lungs can be seen, but other regions that are not of interest for analysis are still present. To solve the problem of eliminating regions that are not of interest, it is necessary to apply some other image processing techniques, including mathematical morphology operations, which will be presented in the next subsection. 


\section{Mathematical morphology operations}

Mathematical morphology operations are a very powerful tool in image analysis and processing since it is responsible for extracting, modifying and combining the components of an image that are useful in the representation and description of a region (Gonzalez \& Woods, 2002). Currently there is a great diversity of applications related to image processing, in which segmentation, contrast enhancement and edge detection are involved. Initially, mathematical morphology operations were developed for binary images and later extended for images at gray levels. These operations allow the extraction of geometric structures from an image to transform or improve them according to some defined purpose, and for this a processing operator known as a structure element or structuring element (SE) is used. The SE is a fully defined assembly characterized by its shape and size and these depend on the purpose of the application. In addition, it has a point of reference known as the origin. In general, the SE is much smaller than the image with which it will interact. The two basic morphological operations are erosion and dilation.

The morphological erosion of an image corresponds to the minimum value of the function within an environment defined by the size and shape of the SE. Erosion is defined as:

$$
I_{S E}^{E}=\min \{I(x+i, y+j)-S E(i, j)\}
$$

The purpose of applying erosion to the binary image is in order to eliminate those regions that are smaller than the structuring element. In this work, the SE that he implemented to interact with the binary image is of the disk type with a radius of one pixel. Figure 5 shows the result of the application of erosion in the binary images.


Figure 5 Erosion process of the binarized image
Once those regions that are smaller than the SE have been eliminated, now the objective is to only leave the regions corresponding to the lungs and to carry out this task it is necessary to apply a technique that eliminates these regions. An unwanted region removal operation is used for this. This is one of the most used applications of morphological reconstruction (Gonzalez \& Woods, 2002). Figure 6 shows the result of eliminating these regions.


Figure 6 Segmentation of lung regions after removal of regions not of interest

In these images, only the regions corresponding to the lung can be seen. Likewise, it is possible to see groups of pixels that belonged to the regions that are not of interest and that were not eliminated in the previous processing. For this, it is necessary to apply operations such as dilation and morphological opening to conclude with the process of correct identification of the regions corresponding to the lung.

The morphological dilation of an image corresponds to the maximum value of the function within an environment defined by the size and shape of the SE. Dilation is defined as:

$I_{S E}^{D}=\max \{I(x+i, y+j)-S E(i, j)\}$

Figure 7 shows the resulting images after applying the dilation process. In these images it can be seen that the gaps that were present have been filled as a product of morphological dilation. Likewise, it can be seen that there are some regions that do not belong to the regions of the lungs and it is necessary to remove them for this, the morphological opening operation is applied.
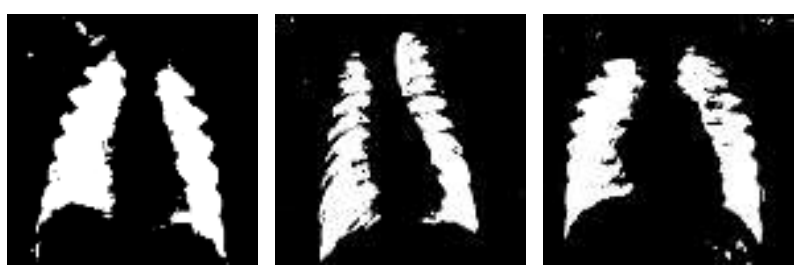

Figure 7 Images resulting from the process of morphological dilation 
The combination of erosion and dilation operations is the basis for creating other operations which are also used for image processing applications. The morphological opening of an image is defined as erosion followed by dilation using the same SE. This operation is expressed as:

\section{$I \circ S E=(I \ominus S E) \oplus S E$}

Where $\ominus$ denotes the erosion operation and $\oplus$ the dilation operation, respectively. The morphological aperture is generally responsible for removing small and clear objects relative to the size of the SE. On the other hand, it maintains the size of large and bright objects. This is due to the fact that the erosion is carried out first and this is in charge of eliminating the small details at the same time that the image darkens and later the dilation is in charge of increasing the brightness, but without introducing the objects eliminated by the erosion (Gonzalez \& Woods, 2002).
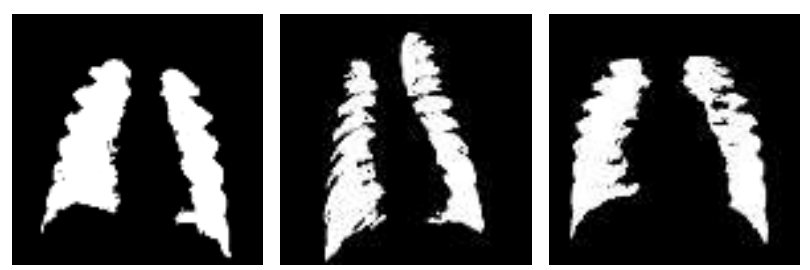

Figure 8 Resulting images after applying the morphological opening process

In Figure 8 you can see the result of the morphological opening where the regions that do not belong to the lungs have been eliminated. On the other hand, it can also be seen that in the regions that correspond to the lung there are some small empty regions. To solve this problem, a region filling technique has been applied and the result can be seen in Figure 9.
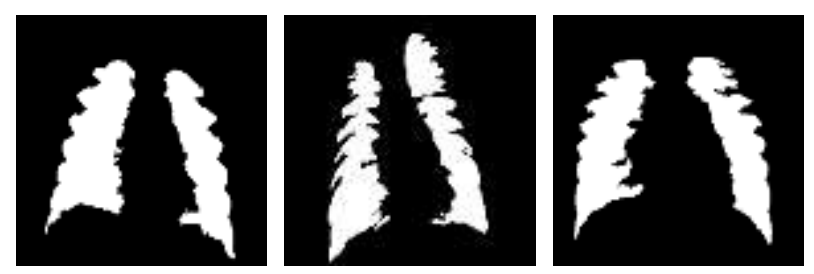

Figure 9 Images resulting from the region fill process
In Figure 9 you can see the regions corresponding to the lung already segmented from the original images. Figure 10 (a) shows the original chest X-ray images. Figure 10 (b) shows only the segmented regions corresponding to lungs obtained with the proposed methodology and highlighted on a black background. Finally, Figure 10 (c) shows the original images with the outline highlighted in red corresponding to the lung regions found with the methodology proposed in this work.
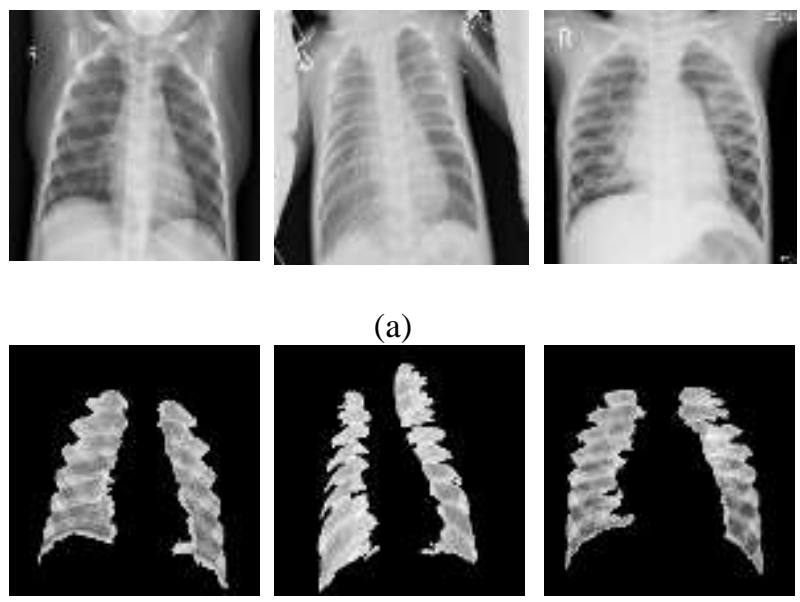

(b)
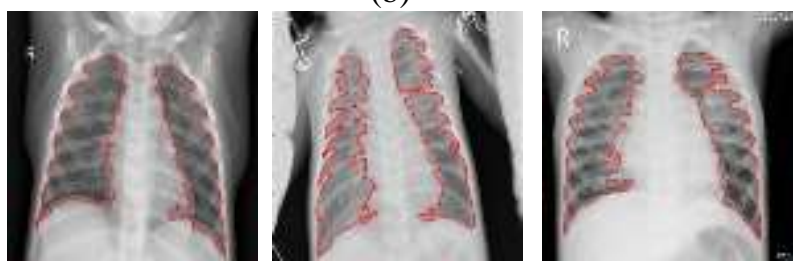

(c)

Figure 10 Result of the segmentation process of the regions corresponding to the lung in chest X-ray through the proposed methodology. (a) Original chest X-ray images. (b) Segmented regions corresponding to lungs obtained with the proposed methodology and highlighted on a black background. (c) Original images with the outline highlighted in red corresponding to the lung regions found with the proposed methodology

\section{Results}

Table 1 shows the analysis of an experiment that was performed with 30 chest $X$-ray images from the database used for this work. 10 of the images correspond to a normal diagnosis, 10 to bacterial pneumonia and 10 to virus pneumonia. 


\begin{tabular}{|c|c|c|c|c|}
\hline \multirow[t]{2}{*}{ Image } & \multirow[t]{2}{*}{ Diagnosis } & \multicolumn{2}{|c|}{$\begin{array}{l}\text { Segmentation of } \\
\text { both lungs }\end{array}$} & \multirow[t]{2}{*}{ Observations } \\
\hline & & Yes & No & \\
\hline 1 & Normal & $\checkmark$ & & \\
\hline 2 & Normal & $\checkmark$ & & \\
\hline 3 & Normal & $\checkmark$ & & \\
\hline 4 & Normal & $\checkmark$ & & \\
\hline 5 & Normal & $\checkmark$ & & \\
\hline 6 & Normal & & $\checkmark$ & $\begin{array}{l}\text { Segment the left } \\
\text { lung }\end{array}$ \\
\hline 7 & Normal & $\checkmark$ & & \\
\hline 8 & Normal & $\checkmark$ & & \\
\hline 9 & Normal & $\checkmark$ & & \\
\hline 10 & Normal & $\checkmark$ & & \\
\hline 11 & Bacterium & & $\checkmark$ & $\begin{array}{l}\text { Segment the left } \\
\text { lung and a couple } \\
\text { of regions of the } \\
\text { right }\end{array}$ \\
\hline 12 & Bacterium & & $\checkmark$ & $\begin{array}{l}\text { Does not segment } \\
\text { either of the two } \\
\text { lungs }\end{array}$ \\
\hline 13 & Bacterium & $\checkmark$ & & \\
\hline 14 & Bacterium & $\checkmark$ & & \\
\hline 15 & Bacterium & & $\checkmark$ & $\begin{array}{l}\text { Does not segment } \\
\text { either of the two } \\
\text { lungs }\end{array}$ \\
\hline 16 & Bacterium & & $\checkmark$ & $\begin{array}{l}\text { Segment the left } \\
\text { lung and a couple } \\
\text { of regions of the } \\
\text { right }\end{array}$ \\
\hline 17 & Bacterium & & $\checkmark$ & $\begin{array}{l}\text { Does not segment } \\
\text { either of the two } \\
\text { lungs }\end{array}$ \\
\hline 18 & Bacterium & & $\checkmark$ & $\begin{array}{l}\text { Segment the left } \\
\text { lung and a couple } \\
\text { of regions of the } \\
\text { right }\end{array}$ \\
\hline 19 & Bacterium & & $\checkmark$ & $\begin{array}{l}\text { Segment only a } \\
\text { couple of regions } \\
\text { of the right }\end{array}$ \\
\hline 20 & Bacterium & & $\checkmark$ & $\begin{array}{l}\text { Does not segment } \\
\text { either of the two } \\
\text { lungs }\end{array}$ \\
\hline 21 & Virus & $\checkmark$ & & \\
\hline 22 & Virus & $\checkmark$ & & \\
\hline 23 & Virus & & $\checkmark$ & $\begin{array}{l}\text { Segment the left } \\
\text { lung and a couple } \\
\text { of regions of the } \\
\text { right }\end{array}$ \\
\hline 24 & Virus & & $\checkmark$ & $\begin{array}{l}\text { Does not segment } \\
\text { either of the two } \\
\text { lungs }\end{array}$ \\
\hline 25 & Virus & $\checkmark$ & & \\
\hline 26 & Virus & $\checkmark$ & & \\
\hline 27 & Virus & & $\checkmark$ & $\begin{array}{l}\text { Segment the left } \\
\text { lung and a couple } \\
\text { of regions of the } \\
\text { right }\end{array}$ \\
\hline 28 & Virus & $\checkmark$ & & \\
\hline 29 & Virus & & $\checkmark$ & $\begin{array}{l}\text { Segment the left } \\
\text { lung }\end{array}$ \\
\hline 30 & Virus & & $\checkmark$ & $\begin{array}{l}\text { Segment the right } \\
\text { lung }\end{array}$ \\
\hline
\end{tabular}

Table 1 Analysis of the results obtained applying the proposed methodology
As can be seen in Table 1, in 16 radiographs the proposed methodology was able to segment the regions corresponding to the lung, of which 9 are with a normal diagnosis, 2 with a diagnosis of bacterial pneumonia and 5 with a diagnosis of viral pneumonia, see Figure 11.

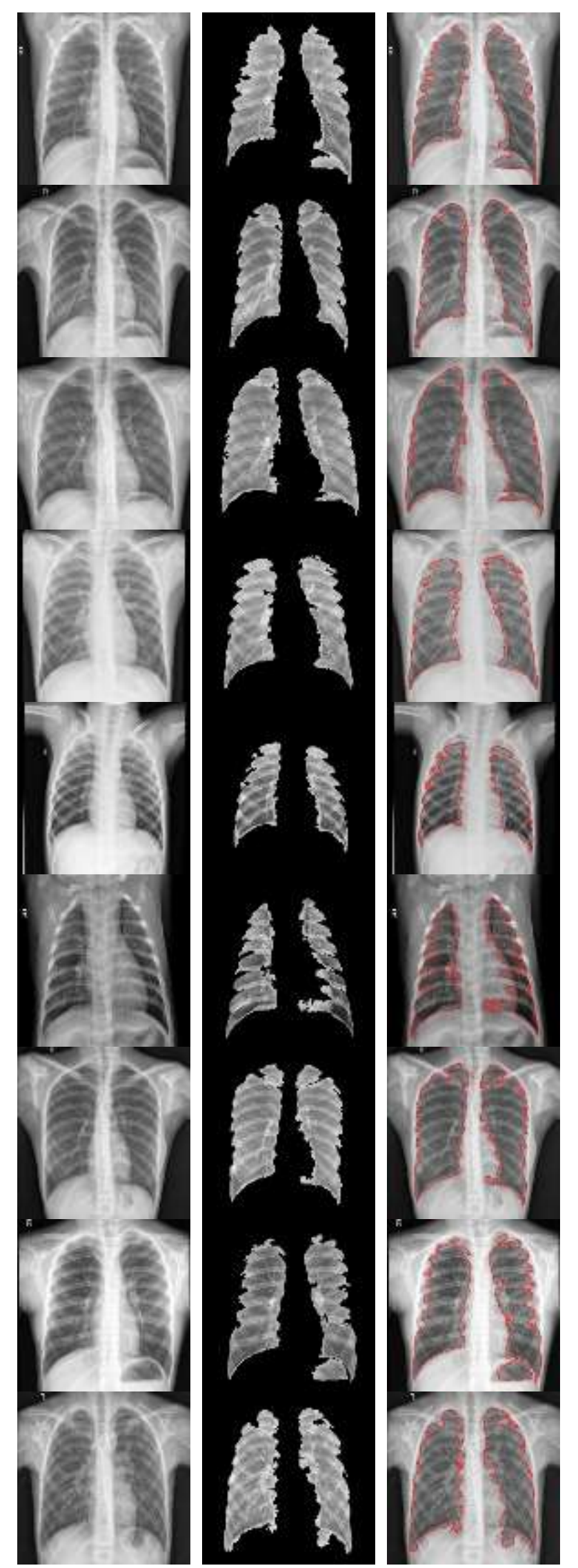

(a) 



(b)

Figure 12 Results of the segmentation of the radiography images applying the proposed methodology detecting only one region corresponding to the lung. (a) Segmentation of a lung with normal diagnosis. (b) Segmentation of a lung diagnosed with viral pneumonia.

In 6 radiographs, he segmented one of the lungs and some regions of the other, of which 4 have a diagnosis of bacterial pneumonia and 2 with a diagnosis of viral pneumonia as shown in Figure 13.


(a)
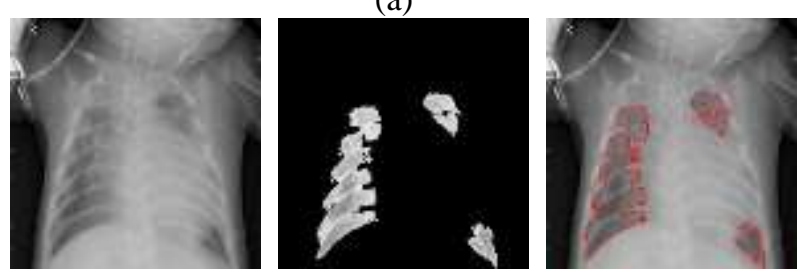

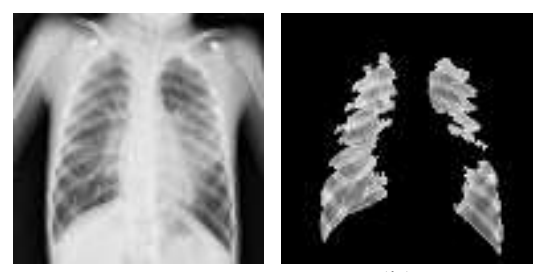

(b)

Figure 13 Results of the segmentation of the X-ray images applying the proposed methodology, detecting only one region corresponding to the lung and some regions of the other lung. (a) Radiographs with a diagnosis of bacterial pneumonia. (b) X-rays with diagnosis of viral pneumonia

Finally, in 5 of the radiographs the methodology does not segment either of the two lungs, of which 3 are diagnosed with bacterial pneumonia and 2 with viral pneumonia.

According to the results obtained by applying the proposed methodology, it can be seen that in $83.3 \%$ of the radiography images used for this work, the regions corresponding to the lung were segmented in a satisfactory way. While $16.6 \%$ failed to detect any of the regions corresponding to the lung.

\section{Conclusions}

In this work, a methodology based on digital image processing techniques for the segmentation of chest radiography images was presented to segment the regions corresponding to the lung. The methodology presented is mainly composed of contrast enhancement, segmentation, binarization, and mathematical morphology operations. According to the results obtained, it is appreciated that the methodology can segment the lung regions with a good percentage. It is evident that the methodology did not manage to segregate all the images as expected, it has areas of opportunity that can be improved by applying some other image processing techniques. On the other hand, it is necessary to have segmented images of the regions corresponding to the lung by experts in order to be able to measure the accuracy of the segmentation of the proposed methodology. Likewise, as future work, an analysis of the regions corresponding to the lung can be proposed through the application of another methodology applying some other image segmentation technique so that the type of lesion found in the region of interest is automatically determined.
Finally, it is concluded that the proposed methodology can be used as an image analysis tool that can be of great help as a complement for the diagnosis of bacterial or viral neumnia due to the disease that is currently causing millions of deaths in the world population. as is COVID-19.

\section{Acknowledgments}

The authors refer to the National Council for Science and Technology (CONACyT), the Department of Engineering in Networks and Telecommunications and the Master's Degree in Engineering (Intelligent Systems) of the Polytechnic University of Juventino Rosas (UPJR) and Dr. César Centeno Fosado and the Nurse Liliana Yañez Vargas of the Salmanca State Center for Critical Care for supporting this work.

\section{References}

Echevarría, A., Miguel , M., Artigao, F., \& del Castillo Martín, F. (2014). Neumonía adquirida en la comunidad. Protocolos diagnósticos terapéuticos de la AEP: Infectología pediátrica., 59-66.

Figueira Gonçalves, J., García-Talavera, I., Golpe, R., \& Gurbani, N. (2020). Síndrome postCOVID en el paciente con enfermedad pulmonar obstructiva crónica: ¿Un caballo de Troya? Medicina de Familia. SEMERGEN, 1-2. doi:https://doi.org/10.1016/j.semerg.2020.10.00 2

Gil, P., Torres, P., \& Ortiz, F. (2004). Detección de Objetos por Segmentación Multinivel Combinada de Espacios de Color. 1-7.

Goërtz, Y., Van Herck, M., Delbressine, J., Vaes, A., Meys, R., Machado, F., \& et al. (2020). Persistent symptoms 3 months after a SARSCoV-2 infection: the post-COVID-19 syndrome? ERJ open research, 1-20.

Gonzalez, R., \& Woods, R. (2002). Digital Image Processing. Prentice-Hall.

Joykutty, B., Satheeshkumar, K., \& Samuvel, B. (2016). Automatic Tuberculosis Detection using Adaptive Thresholding in Chest Radiographs. 2016 International Conference on Emerging Technological Trends (ICETT), (págs. 1-7). 
Mayo Clinic. (21 de Diciembre de 2020). Mayo Clinic. Obtenido de https://www.mayoclinic.org/es-es/diseasesconditions/pneumonia/diagnosis-treatment/drc20354210

Merzban, M., \& Elbayoumi, M. (2019). Efficient solution of Otsu multilevel image thresholding: A comparative study. Expert Systems with Applications, 299-309.

Mooney, P. (24 de Marzo de 2018). Chest X-Ray Images (Pneumonia). Obtenido de https://www.kaggle.com/paultimothymooney/c hest-xray-pneumonia

Naranjo Alcázar, J., Bosch Roig, I., Sanz Requena, R., \& Vázquez Martínez, S. (2016). Método automático de análisis y segmentación de imágenes para la detección de nódulos pulmonares a partir de radiografías de tórax. XXXIV Congreso Anual de la Sociedad Española de Ingeniería Biomédica, (págs. 459462). Valencia.

OMS. (21 de Diciembre de 2020). Organización Mundial de la Salud. Obtenido de https://www.who.int/topics/pneumococcal_infe ctions/es/

Polap, D., \& Wozniak, M. (2017). Lung segmentation on $\mathrm{x}$-ray images with neural validation. Połap, D., \& Woźniak, M. (2017). Lung segmentation on $x$-ray images with neural validation. In 2017 IEEE Symposium Series on Computational Intelligence (SSCI), (págs. 1-7).

Quintanilla, J., Ojeda, B., Ruelas , R., \& Yañez, J. (2019). Contrast enhancement of mammographic images by digital images processing. Journal of Scientific and Technical Applications, 19-28. 